\title{
De-regulation of the sonic hedgehog pathway in the InsGas mouse model of gastric carcinogenesis
}

\author{
M El-Zaatari', A Tobias', AM Grabowska', R Kumari', PJ Scotting², P Kaye ${ }^{3}$, J Atherton ${ }^{4}$, PA Clarke', \\ DG Powe ${ }^{3}$ and SA Watson ${ }^{*, 1}$
}

'Division of Pre-Clinical Oncology, University of Nottingham, Nottingham, UK; ${ }^{2}$ Institute of Genetics, University of Nottingham, Nottingham, UK; ${ }^{3}$ Division of Pathology, University of Nottingham, Nottingham, UK; ${ }^{4}$ Wolfson Digestive Diseases Centre, University of Nottingham, Nottingham, UK

\begin{abstract}
This study investigated sonic hedgehog (Shh) signalling in gastric metaplasia in the insulin-gastrin (InsGas) hypergastrinaemic mouse + I- Helicobacter felis ( $H$. felis) infection. Sonic hedgehog gene and protein expression was reduced in pre-metaplastic lesions from non-infected mice $(90 \%$ gene reduction, $P<0.01$ ) compared to normal mucosa. Sonic hedgehog was reactivated in gastric metaplasia of $H$. felis-infected mice (3.5-fold increase, $P<0.01$ ) compared to pre-metaplastic lesions. Additionally, the Shh target gene, gliomaassociated oncogene (Gli)- I, was significantly reduced in the gastric glands of InsGas mice $(75 \%$ reduction, $P<0.05)$ and reactivated with $H$. felis infection $(P<0.05$, base of glands, $P<0.0$ I stroma of metaplastic glands). The ability of $H$. felis to activate the Shh pathway was investigated by measuring the effect of target cytokine, interleukin-8 (IL-8), on Shh expression in AGS and MGLVAI cells, which was shown to induce Shh expression at physiological concentrations. $H$. felis induced the expression of NF- $\kappa \mathrm{B}$ in inflammatory infiltrates in vivo, and the expression of the IL-8 mouse homologue, protein $\mathrm{KC}$, in inflammatory infiltrates and metaplastic lesions. Sonic hedgehog pathway reactivation was paralleled with an increase in proliferation of metaplastic lesions (I 5.75 vs $4.39 \%$ in infected vs non-infected mice, respectively, $P<0.00$ I). Furthermore, Shh overexpression increased the growth rate of the gastric cancer cell line, AGS. The antiapoptotic protein, bcl-2, was expressed in the stroma of infected mice, along with a second Shh target gene, patched-I ( $P=0.000$ I, stroma of metaplastic gland). This study provides evidence suggesting reactivation of Shh signalling from pre-metaplastic to advanced metaplastic lesions of the stomach and outlines the importance of the Shh pathway as a potential chemoprophylactic target for gastric carcinogenesis.
\end{abstract}

British Journal of Cancer (2007) 96, 1855-186I. doi:I0.1038/sj.bjc.6603782 www.bjcancer.com

Published online 15 May 2007

(c) 2007 Cancer Research UK

Keywords: sonic hedgehog; CCK-2R; pre-malignant; metaplastic; InsGas; H. felis

Gastric cancer is one of the most common forms of cancer worldwide with an incidence of 934000 new cases per year (Parkin et al, 2005). Helicobacter pylori (H. pylori) is a major risk factor linked to gastric carcinogenesis and has been classified by the International Agency for Research on Cancer (IARC) as a carcinogenic bacterium in humans (IARC, 1994).

A number of studies have shown an increase in sonic hedgehog (Shh) production in human gastric tumour biopsies (Ma et al, 2005; Ohta et al, 2005), and high expression of the Shh pathway in gastric tumour cell lines (Berman et al, 2003). The importance of the overexpressed Shh pathway observed in gastric cancer has been demonstrated by the ability of Shh pathway antagonists to suppress growth of gastrointestinal (GI) tumour cell lines and xenografts (Berman et al, 2003; Ma et al, 2005; Ohta et al, 2005).

* Correspondence: Professor SA Watson, Academic Unit of Cancer Studies, D Floor, West Block, Queen's Medical Centre, University Hospital, Nottingham, NG7 2UH, UK.

E-mail: sue.watson@nottingham.ac.uk

Revised 12 April 2007; accepted 12 April 2007; published online 15 May 2007
However, Shh expression was shown to be reduced in premalignant lesions, atrophic gastritis and intestinal metaplasia (van den Brink et al, 2002; Shiotani et al, 2005) and during acute infection with $H$. pylori in Mongolian gerbils (Suzuki et al, 2005). This reduced expression may be partially explained by the loss of Shh pathway-expressing cell types during gastric atrophy and early metaplasia.

In this study, the insulin-gastrin (InsGas) transgenic mouse model of gastric carcinogenesis has been used to study Shh pathway expression during this process. Helicobacter felis $(H$. felis)-infection of InsGas mice enhanced transformation of the gastric mucosa (Wang et al, 2000), and so we aimed to compare Shh pathway activation between pre-metaplastic and pseudopyloric metaplastic lesions in the non-infected and $H$. felis-infected InsGas models, respectively, focussing on Shh target genes, Patched-1 (Ptch-1) and glioma-associated oncogene (Gli)-1 and a factor, which regulates the pathway but which is not a transcriptional target, Gli-3.

We hypothesised that the discrepancy, reported in the literature, in Shh expression between pre-malignant lesions and cancer may be in response to an elevated inflammatory response, which may be able to trigger Shh expression. 


\section{MATERIALS AND METHODS}

\section{Animals}

FVB and InsGas mice were bred, under sterile conditions, within the Academic Unit of Cancer Studies, under Home Office Project License No. 40/2323. Insulin-gastrin mice either remained non-infected, or were infected with $H$. felis (dosed orally with either $1 \times 10^{8}$ colony-forming units of $\mathrm{H}$. felis in brucella broth or equivalent volumes of broth alone on days 1, 3 and 5). Mice were maintained for 10 months and at termination were injected with bromodeoxyuridine (BrdU) $1 \mathrm{~h}$ before sacrifice. Stomach tissue was dissected out and frozen in optimal cutting temperature compound (Bayer plc, Berkshire, UK), by immersion into liquefied Richard-Allan Cytocool II (Apogent, Ipswich, UK) on dry ice. Frozen blocks and cryostat sections were stored at $-80^{\circ} \mathrm{C}$.

\section{Cell culture}

The human gastric adenocarcinoma cell lines AGS (ECACC, Wiltshire, UK) and MGLVA1 (Division of Pre-clinical Oncology, Nottingham University, (Watson et al, 1990)) were routinely cultured in RPMI 1640 culture medium (Gibco, Paisley, UK) containing $10 \%(\mathrm{v} / \mathrm{v})$ heat-inactivated foetal bovine serum (Sigma, Poole, UK) at $37^{\circ} \mathrm{C}$ in $5 \% \mathrm{CO}_{2}$ and humidified conditions. In some experiments, interleukin-8 (IL-8) (R\&D, Abingdon, UK) was added at concentrations of $0.1-10 \mathrm{~nm}$ to cells, which had been plated at $2.5 \times 10^{4}$ cells per well in 24 -well plates and serum-starved overnight.

\section{Navigated laser capture microdissection}

Frozen sections $(10 \mu \mathrm{m})$ were mounted on PALM PEN membrane slides for microdissection using a PALM microdissector (PALM Microlaser Technologies, Bernried, Germany). Sections were airdried, fixed in pre-chilled $\left(-30^{\circ} \mathrm{C}\right) 70 \%$ RNase-free ethanol at room temperature, counterstained with RNase-free toluene blue (Sigma, Poole, UK), and washed in RNase-free PBS. The slides were then baked at $40^{\circ} \mathrm{C}$ for $40 \mathrm{~min}$ before microdissection. Premetaplastic and metaplastic lesions were micro-dissected following characterisation by a pathologist.

\section{RNA extraction and cDNA synthesis}

Dissected tissue was collected in $350 \mu$ l buffer RLT containing $\beta$ mercaptoethanol from an RNEasy microkit (Qiagen). RNA was reverse transcribed using Superscript III reverse transcriptase (Invitrogen, Paisley, UK) according to the manufacturer's instructions.

\section{Quantitative polymerase chain reaction}

Gene expression was quantified using reagents from the quantitative polymerase chain reaction (qPCR) Core kit for SYBR Green I (Eurogentec, Romsey, UK). Primers were designed using Primer Express version 2 (Applied Biosystems, Foster City, CA, USA, Table 1), and PCR assays carried out on a 7500 Sequence Detection System (PE Biosystems, Warrington, UK). Primer efficiency curves were performed, and results expressed relative to the housekeeping gene ( $\beta$-actin for Shh, Gli-1, and Gli-3, and $R P L 13 a$ for Ptch-1) using the $2^{-\Delta \Delta \mathrm{CT}}$ values and relative quantitation (Livak and Schmittgen, 2001) according to the following equation:

Relative gene expression $=\frac{2^{-}\left[\mathrm{Ct}_{\text {(target })}-\mathrm{Ct}_{(\text {reference })}\right]_{\text {test condition }}}{2^{-}\left[\mathrm{Ct}_{(\text {target })}-\mathrm{Ct}_{(\text {reference })}\right]_{\text {reference condition }}}$
Table I Primer sequences

\begin{tabular}{ll}
\hline Primer & Sequence \\
\hline Mouse Shh & Forward: 5'-AGGAACTCACCCCCAATTACAAC-3' \\
Mouse Ptch-1 & Reverse: 5'-AGAGATGGCCAAGGCATTTAACT-3' \\
& Forward: 5'-GTGATTGTGGAAGCCACAGAAA-3' \\
Mouse Gli-l & Forwerse: 5'-TGTCTGGAGTCCGGATGGA-3' \\
Mouse Gli-3 & Reverse: 5'-GGTGGAGGTCTGCGTGGTA-3' \\
Mouse RPLI3A & Forward: 5'-AGGTCAGCTCTGGCCCTTCT-3' \\
& Reverse: 5'-AGGGTCACCAGTGCTGCTCA-3' \\
Mouse $\beta$-actin & Rorward: 5'-GCGCCTCAAGGTGTTGGAT-3' \\
& Foverse: 5'-GAGCAGCAGGGACCACCAT-3' \\
& Reverse: 5'-CCAGCGCAGCGATATCG-3' \\
\hline
\end{tabular}

\section{Antibodies}

Polyclonal antibodies directed against Shh $(\mathrm{N}-19,4 \mu \mathrm{g} / \mathrm{ml})$, protein $\mathrm{KC}(8 \mu \mathrm{g} / \mathrm{ml})$ and CCK-2/gastrin receptor (CCK-2R) (S-20, $12 \mu \mathrm{g} /$ $\mathrm{ml}$ ) were obtained from Santa Cruz (Autogen Bioclear, Wiltshire, UK). Monoclonal antibody directed specifically against the active form of the p65 subunit of NF- $\kappa \mathrm{B}$ was obtained from Chemicon (Harrow, UK). Monoclonal antibodies to BrdU (M0744 $5.56 \mu \mathrm{g} / \mathrm{ml})$ and bcl-2 (M0887 $5.6 \mu \mathrm{g} / \mathrm{ml}$ ) were obtained from Dako (Ely, UK) and binding of primary antibodies was detected using HRPconjugated secondary antibodies (Dako).

\section{Immunohistochemistry}

Sonic hedgehog and CCK-2R staining was performed on frozen sections, whereas bcl-2, BrdU, $\mathrm{KC}$ and $\mathrm{NF}-\kappa \mathrm{B}$ staining was performed on paraffin sections. Paraffin sections were de-waxed in xylene, washed in $100 \%$ ethanol and underwent antigen retrieval in $10 \mathrm{~mm}, \mathrm{pH} 6.0$ citrate buffer. Frozen sections were air-dried and fixed in $4 \%$ paraformaldehyde. Sections were washed in PBS and blocked for endogenous peroxidase activity $\left(1.2 \% \mathrm{H}_{2} \mathrm{O}_{2}\right.$ for $\mathrm{Shh}$ $\mathrm{N}-19$ and $\mathrm{KC}$ antibodies, and $0.06 \% \mathrm{H}_{2} \mathrm{O}_{2}$ for CCK-2R). Sections were then washed in PBS, blocked in $10 \%$ rabbit serum, and incubated with primary antibody. For negative controls, concentration- and species-matched serum or IgG were applied. The sections were washed in PBS, incubated with secondary antibody, and washed again in PBS. Staining was developed using liquid diaminobenzidine (DAB, Dako). Bromodeoxyuridine labelling and active NF- $\kappa \mathrm{B}$ staining was performed using the Ark-labelling kit (Dako).

\section{Construction of Shh-expressing plasmid and stable transfection into AGS cells}

pJT4/Shh, containing the chick Shh insert, was kindly provided by Professor Hiroshi Sasaki. The R-U5 sequence, splicing/intron sequence, and Shh insert were excised by XhoI digestion and ligated into the XhoI site of pcDNA3.1 $(+)$ (Invitrogen), which was confirmed by sequencing. For vector control, pcDNA3.1 $(+)$ was transfected into AGS cells. Transfection was carried out using Lipofectamine 2000 (Invitrogen), and high-expressor colonies chosen for cell-growth analysis following single-cell cloning. Cell growth analysis was performed using 3-(4, 5-dimethylthiazolyl-2)2, 5-diphenyltetrazolium bromide (MTT, Sigma).

\section{Statistical analysis}

Gene expression was analysed by the Mann-Whitney $U$ nonparametric statistical test, proliferation assessed (BrdU uptake) by the Student's $t$-test and MTT uptake by a one-way analysis of variance. 
A

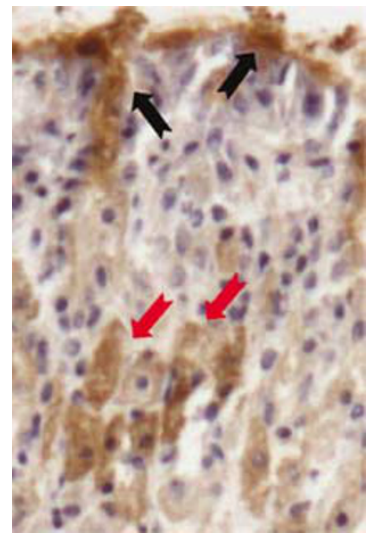

Shh protein is expressed in pit (black arrows) and parietal cells (red arrows) of the isthmus in the normal gastric mucosa of FVB mice.

B

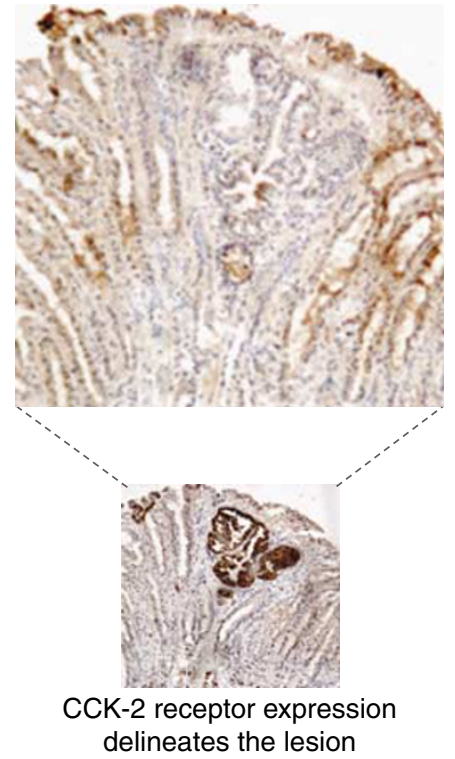

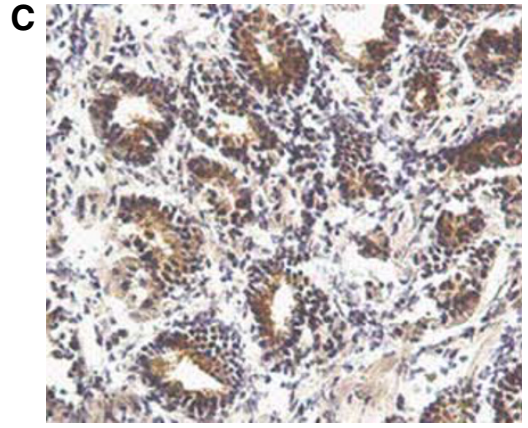

D
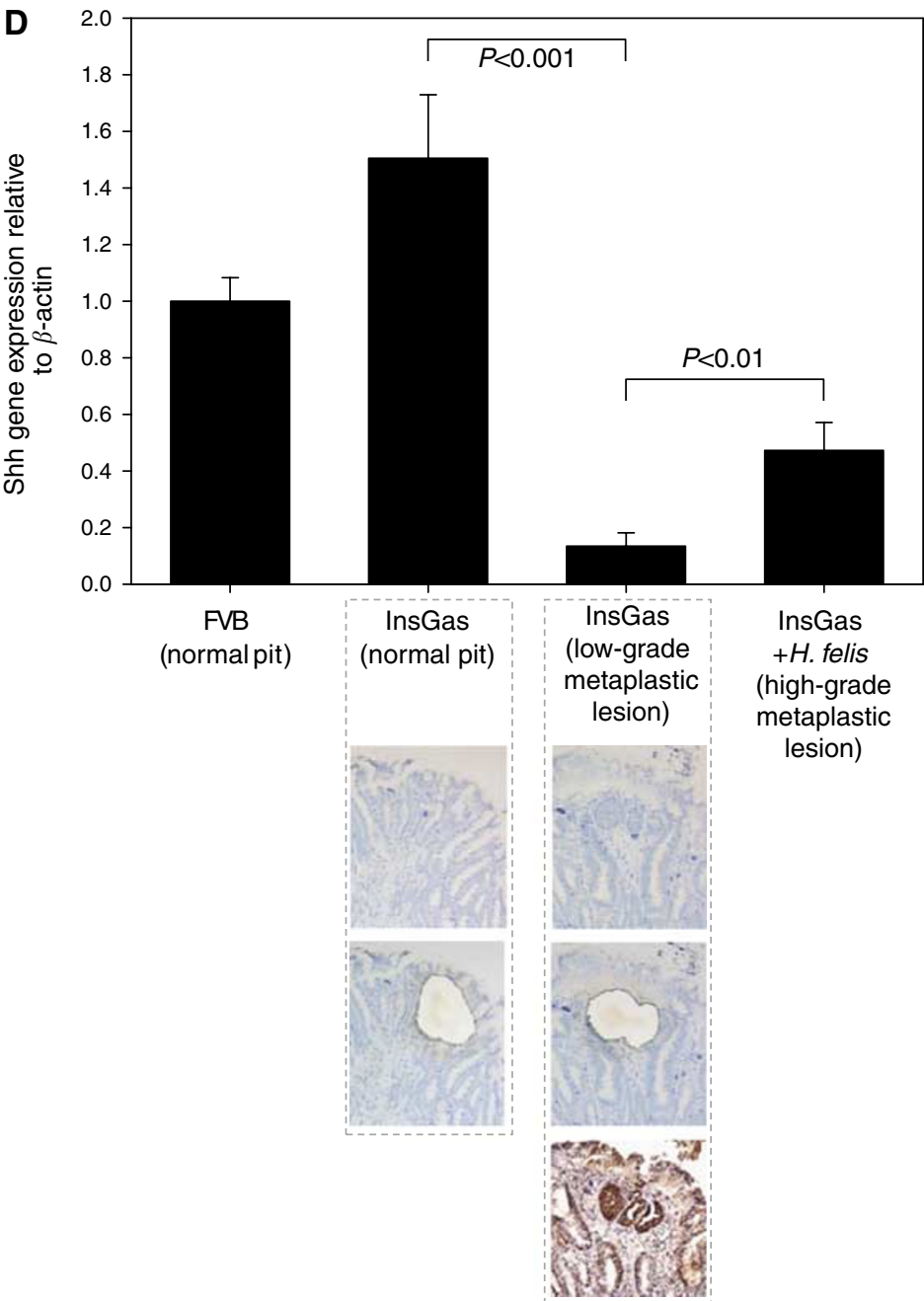

Figure I Expression of Shh in normal and metaplastic gastric mucosa in the InsGas mouse. (A) Shh protein is expressed in pit and parietal cells of the isthmus in the normal gastric mucosa of FVB mice. (B) Loss of Shh protein expression in pre-metaplastic gastric lesions of non-infected InsGas mice (lesion delineated by CCK-2 receptor expression). (C) Reactivation of Shh protein expression in pseudopyloric metaplastic lesions from $H$. felis-infected InsGas mice. (D) CCK-2/gastrin receptor protein expression delineated the lesion in non-infected InsGas, and was used to navigate the microdissection of the lesion for RNA analysis. Tissue from the pit region of normal adjacent glands in the same section was used as a control. RT-PCR analysis of the microdissectates shows a significant $90 \%$ reduction in Shh gene expression in pre-metaplastic lesions from non-infected Ins Gas mice $(P<0.00$ I, Mann-Whitney $U$-test), but a 3.5-fold re-activation in pseudopyloric metaplasia from $H$. felis-infected InsGas $(P<0.01)$. Error bars $=95 \%$ confidence interval.

\section{RESULTS}

\section{Expression of Shh is lost in pre-malignant lesions and reactivated in advanced lesions}

Sonic hedgehog protein was localised to both pit and parietal cells of the normal gastric mucosa (Figure 1A), but was lost in pre- metaplastic lesions of non-infected InsGas mice (as defined by a pathologist and delineated by gastrin/CCK-2R expression) compared to normal adjacent glands (Figure 1B). Pseudopyloric metaplasia in $\mathrm{H}$. felis-infected mice exhibited reactivation of Shh protein expression (Figure 1C). The loss of Shh protein was corroborated at the gene level by laser capture microdissection (LCM) of pre-metaplastic lesions (Figure 1D). Sonic hedgehog gene 
expression was downregulated by greater than $90 \%$ in premetaplastic lesions from non-infected mice compared to normal adjacent tissue from the same section $(P<0.001$, Figure $1 D)$, but was partially recovered in metaplastic lesions of $H$. felis-infected mice (3.5-fold increase, $P<0.01$, Figure 1D).

\section{H. felis infection may enhance Shh expression via the upregulation of mouse IL-8 homologue, protein $\mathrm{KC}$, in infiltrating inflammatory cells}

$H$. felis infection increased the expression of NF- $\kappa \mathrm{B}$ and the IL- 8 homologue, $\mathrm{KC}$, in infiltrating cells at the base of gastric glands (Figure $2 \mathrm{~A}$ and $\mathrm{B}$ ), and in the stroma surrounding pre-metaplastic lesions (Figure $2 \mathrm{C}$ and $\mathrm{D}$ ). $\mathrm{KC}$ was also expressed in pre-metaplastic lesions (Figure 2D) where Shh was detected (Figure 1C). No staining was seen in these areas in the negative controls. Interleukin-8 treatment of AGS and MGLVA1 cells significantly increased Shh gene expression at physiological levels (nM) (Figure 2E).

\section{Expression of Gli-transcription factors during gastric carcinogenesis}

The highest expression of Gli-1 and Gli-3 was detected in the base region of normal murine gastric mucosa (Figure 3A). Gli-1 and Gli3 gene expression was measured in microdissected base tissue from gastric units of InsGas mice with/without $H$. felis infection (Figure 3B and C). Target Gli-1 expression was significantly reduced in the base of normal gastric units in both non-infected (73\% inhibition, $P<0.05)$ and $H$. felis-infected InsGas mice $(75 \%$ inhibition, $P<0.05$ ) (Figure $3 \mathrm{~B}$ ). Expression of Gli-1 was reactivated in the base region of metaplastic lesions in infected mice, compared with adjacent normal regions (3.3-fold increase, $P<0.05$, Figure 3B).

The expression of Gli-3 RNA was also reduced with increasing malignant potential (normal base of gastric units in both noninfected and infected InsGas mice, $P<0.05$ when compared to normal base from wild-type FVB mice, Figure 3C). Expression was
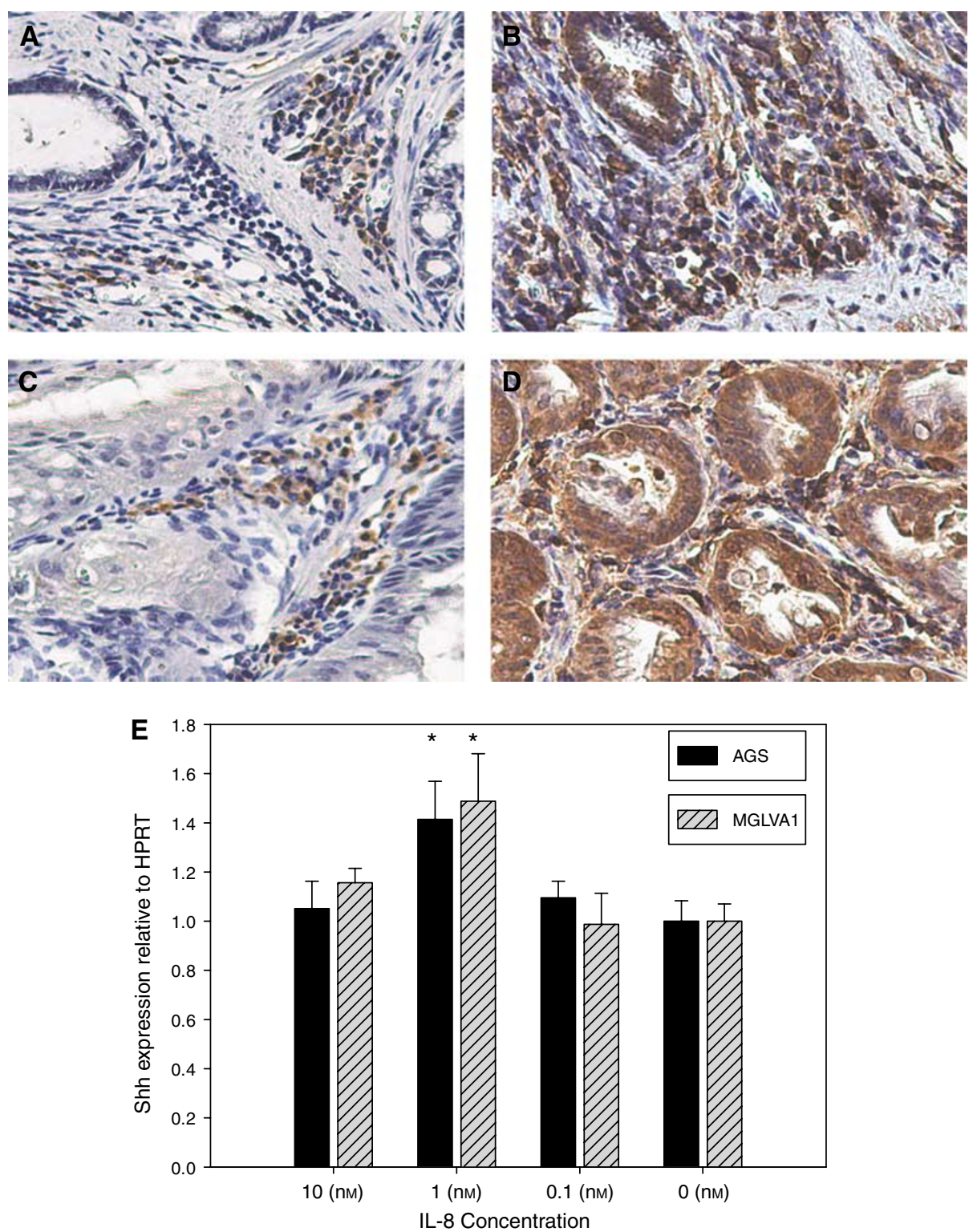

Figure 2 Upregulation of NF- $\kappa$ B in $H$. felis infection. Expression of NF- $\kappa \mathrm{B}(\mathbf{A}, \mathbf{C})$ and IL-8 $(\mathbf{B}, \mathbf{D})$ in infiltrating cells at the base of gastric glands $(\mathbf{A}, \mathbf{B})$ and the stroma surrounding pre-metaplastic lesions $(\mathbf{C}, \mathbf{D})$ during $\mathrm{H}$. felis infection, IL-8 staining is also present in pre-metaplastic lesions $(\mathbf{D})$, magnification $\times 20$. Sonic hedgehog gene expression was upregulated in AGS and MGLVAI gastric cell lines (E) following treatment with I nM IL-8 (*P $<0.000 \mathrm{I})$. 

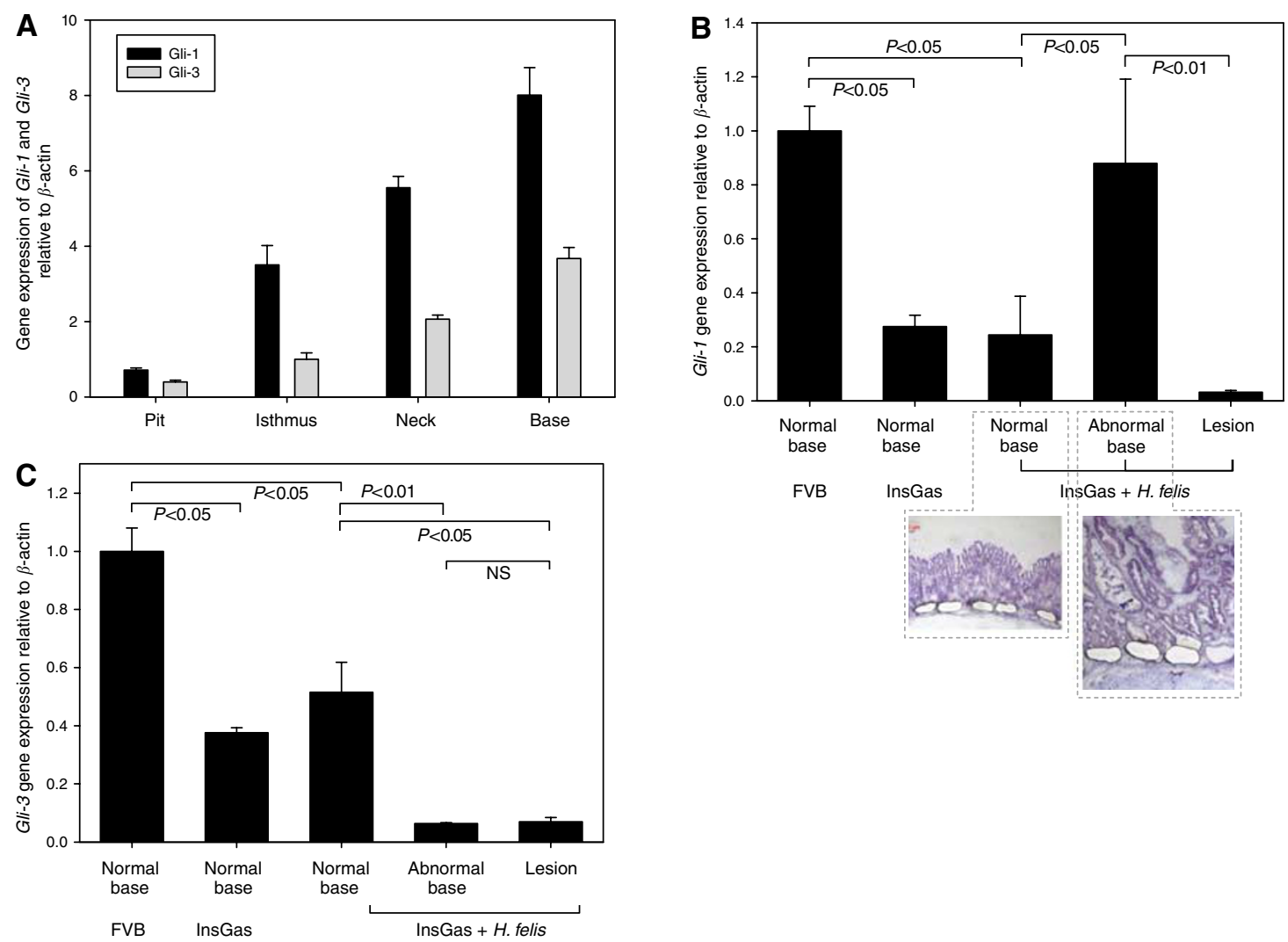

Figure 3 Gli-transcription factor gene expression in metaplastic progression in the InsGas mouse. (A) Relative expression of Gli-I and Gli-3 in the normal mucosa showing highest expression of each factor at the base of gastric glands. (B) Gli-I gene expression is reduced in the normal base of Ins Gas mice ( $\pm H$. felis infection) but reactivated in the base region associated with pseudopyloric metaplasia ( $P<0.05$, Mann-Whitney $U$-test). (C) Gli-3 expression is reduced with increasing malignant potential and not reactivated in pseudopyloric metaplasia. Error Bars $=95 \%$ confidence limits, NS = nonsignificant.

not reactivated in the base region of abnormal gastric glands or metaplastic lesions in $H$. felis-infected InsGas mice (Figure 3C).

Enhanced cell growth and antiapoptotic activity in advanced lesions may be attributed to paracrine Shh signalling

The percentage of proliferating cells was significantly higher in pseudopyloric metaplasia in $\mathrm{H}$. felis-infected when compared to pre-metaplastic lesions in non-infected InsGas mice (15.76 vs $4.39 \%, P<0.001$, Figure $4 \mathrm{~A}$ and visually depicted in B). In accordance with this, Shh overexpression in the human gastric adenocarcinoma cell line, AGS, promoted growth significantly compared with vector control-transfected cells in serum free medium (Figure 4C, $P<0.0001$ ).

Apoptotic potential was determined by examining bcl-2 expression, a known down-stream, antiapoptotic factor associated with hedgehog signalling (Bastida et al, 2004) and expression was confirmed in the stroma associated with metaplastic lesions in infected but not non-infected mice (Figure 4B). The stroma was subjected to LCM and it was shown that whereas Shh was not expressed, Shh target genes, Ptch-1 and Gli-1, were co-expressed in the stroma surrounding Shh-expressing lesions in $\mathrm{H}$. felis-infected InsGas mice (Figure 4D).

\section{DISCUSSION}

This study has confirmed that Shh expression and signalling is reduced in early pre-metaplastic lesions in non-infected InsGas mice as shown previously (van den Brink et al, 2002; Shiotani et al, 2005). However, in pseudopyloric metaplastic lesions arising in $H$. felis-infected mice, Shh is re-expressed, together with distinct expression of the down-stream target gene, Gli-1, in the base and associated stroma, suggesting paracrine activity.

Previous studies have confirmed that Shh and its target gene Ptch-1 are upregulated in inflamed tissues of the GI tract (Nielsen et al, 2004) with human gastritic epithelium (including that associated with $H$. pylori infection) shown to strongly express Shh. This may be a direct effect of infection, as Helicobacter activates $\mathrm{NF}-\kappa \mathrm{B}$ via chronic inflammation and the activation of interleukins, such as IL-4 (Lee et al, 2005), or in response to lipopolysaccharides (Hynes et al, 2004) and NF- $\kappa \mathrm{B}$ in turn is able to activate Shh (Nakashima et al, 2006). We have shown in this study that one mechanism may be via the activation of NF- $\kappa \mathrm{B}$ and its transcriptional target, IL-8 (Aihara et al, 1997; Chu et al, 2003), in infiltrating inflammatory cells surrounding the lesions, as IL-8 was shown to induce Shh gene expression in gastric adenocarcinoma cells.

Functional Shh signalling was confirmed, as the hedgehog target, Gli-1, was re-expressed in the base and stroma of pseudopyloric metaplastic lesions in $\mathrm{H}$. felis-infected mice, in contrast to Gli-3, which is not a transcriptional target of the Shh pathway, and which maintained low expression.

Gli-1 is known to induce expression of proliferative genes such as cyclin D2 (Yoon et al, 2002), FOXM1 and the ras-ERK pathway (Xie et al, 2001; Teh et al, 2002) and to reduce expression of cell cycle repressor p21/CIP1 in gastric carcinoma cell lines (Ohta et al, 2005). Gli-1 was also shown to potentiate the malignant phenotype via its antiapoptotic activity in gastric tumour cells (Ma et al, 
A

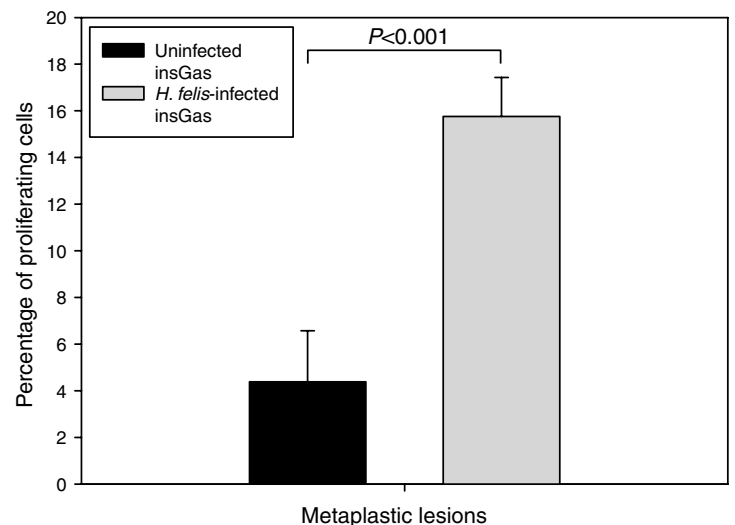

Metaplastic lesions

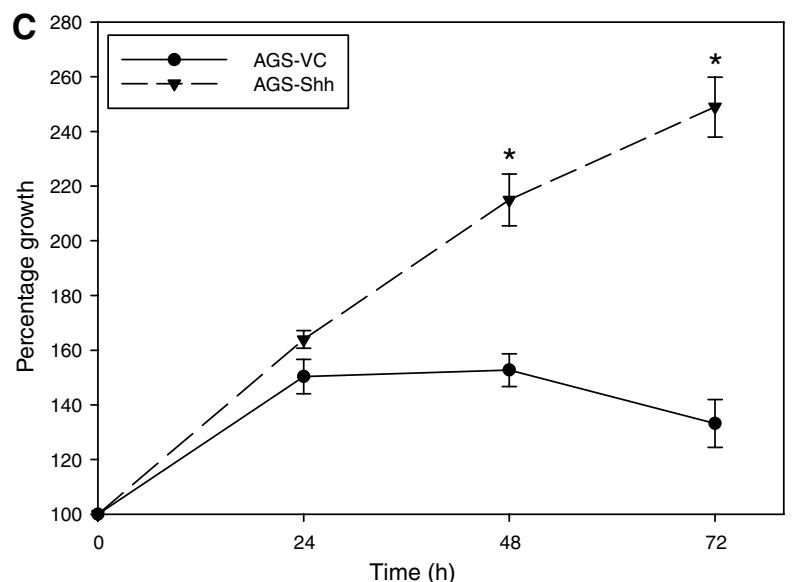

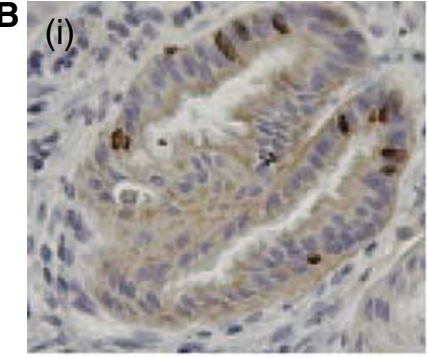
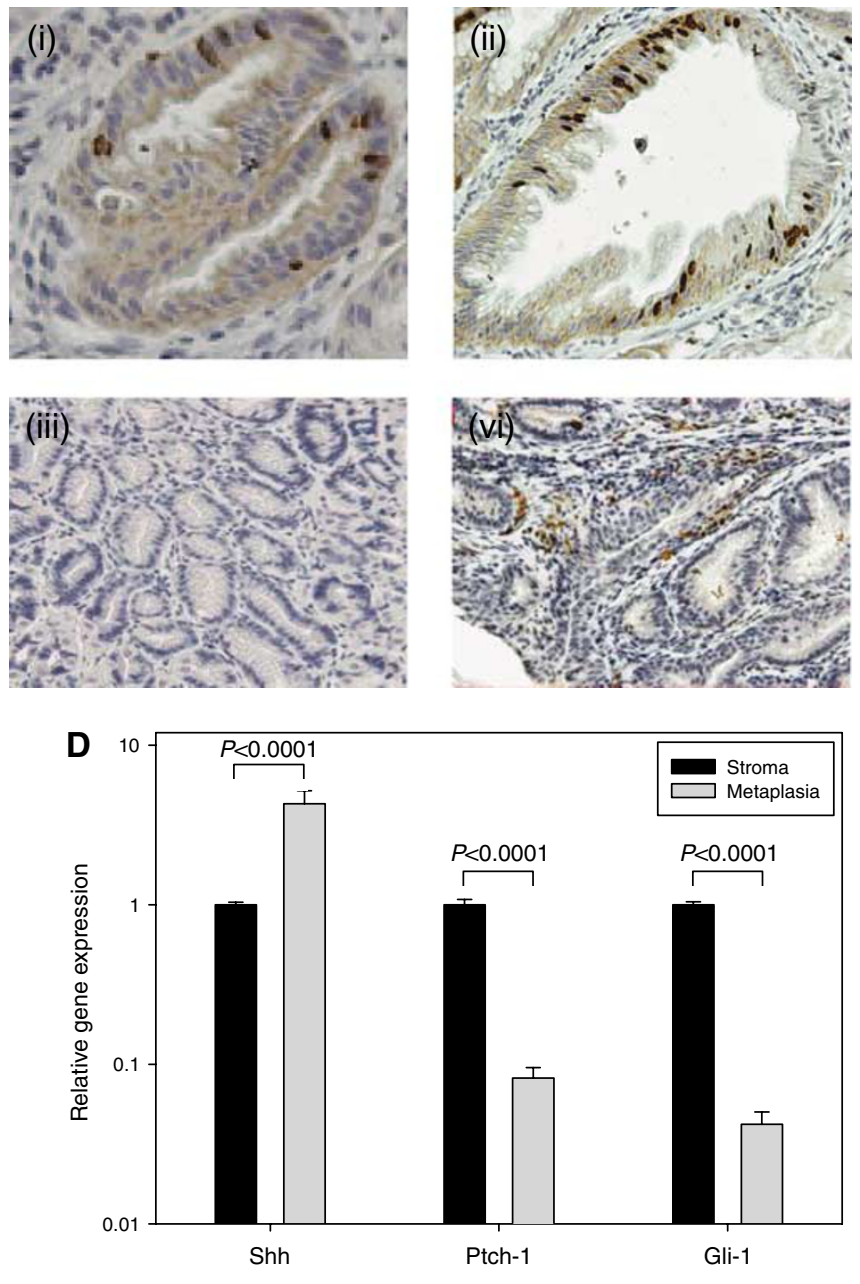

Figure 4 Proliferation rate and bcl-2 expression in metaplastic glands of the InsGas mouse and hedgehog pathway gene expression in associated stroma. (A) Proliferation rate was increased significantly in pre-metaplastic lesions of $H$. felis-infected compared to non-infected InsGas mice ( $P<0.001$, Student's t-test). (B) Proliferative nuclei and bcl-2 expression in H. felis-infected (ii and iv) compared to non-infected (i and iii) InsGas mice, respectively. Magnification $\times 20$. (C) Sonic hedgehog-transfected AGS cells exhibit an increased growth rate compared with vector control-transfected cells $(P<0.000$ I, one-way analysis of variance). (D) Expression of Shh, Ptch-I and Gli-I in pseudopyloric metaplastic lesions compared to the surrounding stroma. Error bars $=95 \%$ confidence intervals.

2005). In the present study, there was a higher rate of proliferation and antiapoptotic activity in metaplastic compared with in premetaplastic lesions in non-infected mice and Shh overexpression increased the growth rate of a gastric cell line.

In contrast to Gli-1, the proapoptotic factor, Gli-3, which is not a transcriptional target of the hedgehog pathway, was not reactivated in metaplastic glands. This may therefore result in a switch to an antiapoptotic, proproliferative phenotype as Gli-3 repressor activity is associated with an increased level of proapoptotic BMP-4 (Bastida et al, 2004). Furthermore, in reduced Shh signalling, Ptch-1 can induce an apoptotic signal through Gli-3 (Kalderon, 2004). Gli-3 also inhibits Gli-1's ability to upregulate bcl-2 transcription in basal cell carcinoma (Bastida et al, 2004).

Interestingly, Ptch-1 and Gli-1, both transcriptional targets of hedgehog signalling were overexpressed in the stroma surrounding metaplastic lesions in $\mathrm{H}$. felis infected but not in non-infected mice and paralleled an upregulation of bcl-2 expression. Although the cell type(s) responsible for expression were not confirmed in the present study, Ptch-1 is known to be expressed by infiltrating immune cells (Stewart et al, 2002), which could be responsible for this expression. Furthermore, enhanced bcl-2 expression may be as a result of Gli-1 re-expression as confirmed in gastric carcinoma cells (Ohta et al, 2005).

Finally, we detected Shh expression in pit and parietal cells of the gastric mucosa, whereas a recent study has detected Shh only in parietal cells (Fukaya et al, 2006). Sonic hedgehog has previously been reported to be absent in pit cells in one study (van den Brink et al, 2001), whereas another study detected Shh expression in the pit region of Mongolian gerbils by in situ hybridisation (Suzuki et al, 2005). The expression of Shh in the pit may differ between FVB mice utilised in this study and mouse strains utilised in other studies (van den Brink et al, 2001; Fukaya et al, 2006). We have, however, confirmed Shh RNA expression by LCM, in which high expression of Shh was detected in the pit region of FVB mice. The discrepancy may also be attributed to the specificity of the antibodies in question, which may crossreact with Ihh (Van Den Brink and Peppelenbosch, 2006). The expression of Gli-1 was also detected in this study by LCM throughout the gastric gland, with highest expression in base cells. This correlates with Gli-1 expression detected in a recent study (Yanai et al, 2007), but disagrees with observations made by Fukaya et al (2006) that Gli-1 expression is absent in the isthmus/neck region. The pattern of 
Gli-1 expression in this study was obtained consistently in different samples using quantitative RT-PCR and primers that span the exon-exon junctions to avoid genomic contamination. Samples also underwent DNase treatment, and primers were designed not to overlap with homologous genes, Gli-2 and Gli-3. Therefore, the reason for the discrepancy remains unclear, but we speculate that this may be attributed to the sensitivity of detection of gene expression using quantitative or classical PCR, the former being normalised against housekeeping gene expression, whereas the latter is dependent on the relative amount of cDNA loaded into the reaction.

We propose that Shh expression is downregulated in premetaplastic gastric lesions in the InsGas mouse, with an associated decrease in Gli-1 expression. In pseudopyloric metaplasia, as a result of $H$. felis infection, Shh is reactivated and may signal, in a paracrine manner, to activate Gli-1 in the stroma and the base regions. Reactivation of Shh may be mediated by the induction of inflammatory cytokines in response to $\mathrm{H}$. felis infection. This study suggests that the Shh pathway is reactivated in pseudopyloric metaplasia, and may contribute to gastric carcinogenesis and therefore may be an appropriate chemoprophylactic target.

\section{ACKNOWLEDGEMENTS}

We acknowledge CORE for funding this research and Jane McClelland from the Academic Unit of Cancer Studies for her input into the preparation of this paper.

\section{REFERENCES}

Aihara M, Tsuchimoto D, Takizawa H, Azuma A, Wakebe H, Ohmoto Y, Imagawa K, Kikuchi M, Mukaida N, Matsushima K (1997) Mechanisms involved in Helicobacter pylori-induced interleukin-8 production by a gastric cancer cell line, MKN45. Infect Immun 65: 3218-3224

Bastida MF, Delgado MD, Wang B, Fallon JF, Fernandez-Teran M, Ros MA (2004) Levels of Gli3 repressor correlate with Bmp4 expression and apoptosis during limb development. Dev Dyn 231: 148-160

Berman DM, Karhadkar SS, Maitra A, Montes De Oca R, Gerstenblith MR, Briggs K, Parker AR, Shimada Y, Eshleman JR, Watkins DN, Beachy PA (2003) Widespread requirement for Hedgehog ligand stimulation in growth of digestive tract tumours. Nature 425: 846-851

Chu SH, Kim H, Seo JY, Lim JW, Mukaida N, Kim KH (2003) Role of NFkappaB and AP-1 on Helicobater pylori-induced IL-8 expression in AGS cells. Dig Dis Sci 48: 257-265

Fukaya M, Isohata N, Ohta H, Aoyagi K, Ochiya T, Saeki N, Yanagihara K, Nakanishi Y, Taniguchi H, Sakamoto H, Shimoda T, Nimura Y, Yoshida $\mathrm{T}$, Sasaki H (2006) Hedgehog signal activation in gastric pit cell and in diffuse-type gastric cancer. Gastroenterology 131: 14-29

Hynes SO, Ferris JA, Szponar B, Wadstrom T, Fox JG, O’Rourke J, Larsson L, Yaquian E, Ljungh A, Clyne M, Andersen LP, Moran AP (2004) Comparative chemical and biological characterization of the lipopolysaccharides of gastric and enterohepatic helicobacters. Helicobacter 9: $313-323$

IARC (1994) Infection with Helicobacter pylori. IARC Monogr Eval Carcinog Risks Hum 61: 177-179

Kalderon D (2004) Hedgehog signaling: Costal-2 bridges the transduction gap. Curr Biol 14: R67 - R69

Lee SO, Lou W, Nadiminty N, Lin X, Gao AC (2005) Requirement for NF(kappa)B in interleukin-4-induced androgen receptor activation in prostate cancer cells. Prostate 64: $160-167$

Livak KJ, Schmittgen TD (2001) Analysis of relative gene expression data using real-time quantitative PCR and the 2(-Delta Delta C(T)) Method. Methods 25: $402-408$

Ma X, Chen K, Huang S, Zhang X, Adegboyega PA, Evers BM, Zhang H, Xie $J$ (2005) Frequent activation of the hedgehog pathway in advanced gastric adenocarcinomas. Carcinogenesis 26: $1698-1705$

Nakashima H, Nakamura M, Yamaguchi H, Yamanaka N, Akiyoshi T, Koga K, Yamaguchi K, Tsuneyoshi M, Tanaka M, Katano M (2006) Nuclear factor-kappaB contributes to hedgehog signaling pathway activation through sonic hedgehog induction in pancreatic cancer. Cancer Res 66: $7041-7049$

Nielsen CM, Williams J, van den Brink GR, Lauwers GY, Roberts DJ (2004) Hh pathway expression in human gut tissues and in inflammatory gut diseases. Lab Invest 84: $1631-1642$

Ohta M, Tateishi K, Kanai F, Watabe H, Kondo S, Guleng B, Tanaka Y, Asaoka Y, Jazag A, Imamura J, Ijichi H, Ikenoue T, Sata M, Miyagishi M, Taira K, Tada M, Kawabe T, Omata M (2005) p53-Independent negative regulation of $\mathrm{p} 21 / \mathrm{cyclin}$-dependent kinase-interacting protein 1 by the sonic hedgehog-glioma-associated oncogene 1 pathway in gastric carcinoma cells. Cancer Res 65: $10822-10829$

Parkin DM, Bray F, Ferlay J, Pisani P (2005) Global cancer statistics, 2002. CA Cancer J Clin 55: 74-108

Shiotani A, Iishi H, Uedo N, Ishiguro S, Tatsuta M, Nakae Y, Kumamoto M, Merchant JL (2005) Evidence that loss of sonic hedgehog is an indicator of Helicobacter pylori-induced atrophic gastritis progressing to gastric cancer. Am J Gastroenterol 100: 581-587

Stewart GA, Lowrey JA, Wakelin SJ, Fitch PM, Lindey S, Dallman MJ, Lamb JR, Howie SE, Hoyne GF (2002) Sonic hedgehog signaling modulates activation of and cytokine production by human peripheral CD4+ T cells sonic hedgehog promotes cell cycle progression in activated peripheral CD4(+) T lymphocytes. J Immunol 169: 5451-5457

Suzuki H, Minegishi Y, Nomoto Y, Ota T, Masaoka T, van den Brink GR, Hibi T (2005) Down-regulation of a morphogen (sonic hedgehog) gradient in the gastric epithelium of Helicobacter pylori-infected Mongolian gerbils. J Pathol 206: $186-197$

Teh MT, Wong ST, Neill GW, Ghali LR, Philpott MP, Quinn AG (2002) FOXM1 is a downstream target of Gli1 in basal cell carcinomas. Cancer Res 62: $4773-4780$

van den Brink GR, Hardwick JC, Nielsen C, Xu C, ten Kate FJ, Glickman J, van Deventer SJ, Roberts DJ, Peppelenbosch MP (2002) Sonic hedgehog expression correlates with fundic gland differentiation in the adult gastrointestinal tract. Gut 51: 628-633

van den Brink GR, Hardwick JC, Tytgat GN, Brink MA, Ten Kate FJ, Van Deventer SJ, Peppelenbosch MP (2001) Sonic hedgehog regulates gastric gland morphogenesis in man and mouse. Gastroenterology 121: 317-328

Van Den Brink GR, Peppelenbosch MP (2006) Expression of hedgehog pathway components in the adult colon. Gastroenterology 130: 619

Wang TC, Dangler CA, Chen D, Goldenring JR, Koh T, Raychowdhury R, Coffey RJ, Ito S, Varro A, Dockray GJ, Fox JG (2000) Synergistic interaction between hypergastrinemia and Helicobacter infection in a mouse model of gastric cancer. Gastroenterology 118: 36-47

Watson SA, Durrant LG, Morris DL (1990) The effect of the E2 prostaglandin enprostil, and the somatostatin analogue SMS 201995 , on the growth of a human gastric cell line, MKN45G. Int J Cancer 45: $90-94$

Xie J, Aszterbaum M, Zhang X, Bonifas JM, Zachary C, Epstein E, McCormick F (2001) A role of PDGFRalpha in basal cell carcinoma proliferation. Proc Natl Acad Sci USA 98: 9255-9259

Yanai K, Nagai S, Wada J, Yamanaka N, Nakamura M, Torata N, Noshiro H, Tsuneyoshi M, Tanaka M, Katano M (2007) Hedgehog signaling pathway is a possible therapeutic target for gastric cancer. J Surg Oncol 95: 55-62 Yoon JW, Kita Y, Frank DJ, Majewski RR, Konicek BA, Nobrega MA, Jacob $\mathrm{H}$, Walterhouse D, Iannaccone P (2002) Gene expression profiling leads to identification of GLI1-binding elements in target genes and a role for multiple downstream pathways in GLI1-induced cell transformation. J Biol Chem 277: 5548-5555 